Sharif University of Technology
Scientia Iranica
SCIENTIA
I RAN I CA
http://scientiairanica.sharif.edu

\title{
Evaluation of UV aging behaviors of polyphosphoric acid (PPA) modified asphalt and its asphalt mixture
}

\author{
S. Liu ${ }^{\mathrm{a}, *}, \mathrm{Y} \cdot \mathrm{Xu}{ }^{\mathrm{b}}$, and S. Zhou \\ a. College of Civil and Transportation Engineering, Hohai University, No. 1 Xikang Road, Nanjing, Jiangsu, 210098, China. \\ b. Zhejiang Scientific Research Institute of Transport, No. 188, Gangyang Road, Linan, Hangzhou, Zhejiang, 310006, China. \\ c. Guangxi Key Laboratory of Road Structure and Materials, No. 6, Gaoxin Road, Nanning, Guangxi, 530007, China.
}

Received 5 January 2018; received in revised form 4 June 2018; accepted 17 December 2018

\section{KEYWORDS}

Asphalt;

Asphalt mixture;

Polyphosphoric acid;

Ultraviolet aging;

FTIR;

Thermal properties.

\begin{abstract}
Effects of Polyphosphoric Acid (PPA) on the ultraviolet (UV) aging properties of asphalt and asphalt mixture were studied. The morphologies of these binders were characterized by Fourier Transform Infrared Spectroscopy (FTIR) spectra and ThermoGravimetric (TG) analysis. Then, the effects of PPA on asphalt and its mixture before and after UV aging were investigated in terms of the physical properties and pavement performances. Results showed that the mechanisms of PPA-modified asphalt were physical and chemical reactions; both UV aging and PPA additive could prompt the polycondensation of light components in asphalt. Compared to control samples, the introduction of PPA enhances the asphalt properties and intensifies the asphalt mixture performance. Furthermore, the asphalt performance aging variations (penetration aging index, softening point increment, ductility aging index, and $\mathrm{G}^{*} / \sin \delta$ aging index) decreased significantly due to the introduction of PPA. It was shown that the effects of UV aging on the behaviors of asphalt and asphalt mixture were constrained with the addition of PPA by inhibiting the increase of carbonyl in the oxidation process.
\end{abstract}

(C) 2020 Sharif University of Technology. All rights reserved.

\section{Introduction}

Characterized by excellent performance and long-term service capability of flexible pavement, asphalt binder has been used as the priority choice for pavement material. However, asphalt, like other high molecular compounds, is prone to aging with time in the natural environment synthesized by heat, moisture, oxygen, and sunlight irradiation [1]. According to a survey, aging phenomenon of asphalt inevitably appears in the periods of storage, mixing, paving, and service, which

\footnotetext{
*. Corresponding author. Tel.: +8613611584498 E-mail addresses: lsjwork@hhu.edu.cn (S.Liu); xys0613@126.com (Y.Xu); zhoushengbo2005@163.com (S. Zhou)
}

doi: $10.24200 /$ sci. 2018.50195 .1566 leads to physical hardening and embrittlement [2]. This will decrease the asphalt properties such as hightemperature rutting and low temperature cracking and further shorten the lifetime of pavement.

To characterize the actual aging of asphalt, some laboratory aging methods such as Thin-Film Oven Test (TFOT), Rolling Thin Film Oven Test (RTFOT), and Pressure Aging Vessel (PAV) were employed to simulate the short-term and long-term aging [3]. In detail, TFOT or RTFOT represents short-term aging at construction stages such as mixing, transport, and paving, while PAV reports the long-term aging in the service period of pavement. Asphalt aging, especially long-term aging, is a complicated process in reality. Except for heat and oxygen, ultraviolet (UV) radiation and rainwater, in particular, have important effects on asphalt performances in different zones [4]. In particular, UV radiation is a well-known trigger of 
signaling responses in materials aging and has been proven to affect the asphalt pavement inevitably when directly exposed to sunlight [5]. However, common aging methods are only hot oxygen aging that could not reflect the effect of UV light [6,7]. Therefore, additional UV aging methods are often employed to simulate the effect of long-term climate-induced aging of asphalt.

Conventional asphalt material cannot meet the requirements of increasing traffic and heavy traffic loading [8]. As a result, many polymers or modifiers are used for asphalt modification and have been proved to work as an effective method. Due to its superior performance, Polyphosphoric Acid (PPA) has been researched and used as a modifier recently [9]. Previous researches have examined the effects of PPA on asphalt performance, and the results showed that the early rutting potential, fatigue cracking, and low-temperature cracking of asphalt pavement were reduced [10-13]. However, similar to conventional asphalt, PPA-modified asphalt will also suffer aging when exposed to the natural environment [14-16]. Although there is growing demand for the application of PPA, research on the performance of UV aged PPAmodified asphalt is limited at this stage. Given that there are many areas with higher UV irradiation in China [17], the effect of UV aging on PPA-modified asphalt pavement should be given more attention.

The primary purpose of this research is to determine the UV aging behavior of PPA-modified asphalt and its asphalt mixture. Asphalt was manufactured with PPA and aged first using RTFO; then, UV aging was used to simulate the long-term aging. Microanalysis methods such as Fourier Transform Infrared Spectroscopy (FTIR) and Thermo-Gravimetric (TG) were used to analyze the PPA modification and UV aging mechanism. Conventional experiments as well as softening point, penetration, ductility, and Dynamic Shear Rheometer (DSR) were used to determine the UV aging performance of asphalt. Then, the UV aging performances of asphalt pavement were evaluated through the wheel tracking test, bending beam test, freeze-thaw splitting test, and fatigue test.

\section{Materials and preparation}

\subsection{Materials}

Pure asphalt (labeled PB) and commercial SBSmodified asphalt (labeled PMB) obtained from a refinery were utilized in this research. Table 1 shows the main physical properties of both bitumens.

PPA used in this research was provided by Changzhou Wujin Huayang Chemical CO., Ltd, Jiangsu, China. The PPA concentration calculated by $\mathrm{P}_{2} \mathrm{O}_{5}$ was $84 \%$.

Crushed basalt aggregate and calcium carbonate $\left(\mathrm{CaCO}_{3}\right)$ filler were used to prepare the asphalt mix-
Table 1. Properties of the three asphalt binders.

\begin{tabular}{lcc}
\hline \multirow{2}{*}{ Test properties } & \multicolumn{2}{c}{ Test results } \\
\cline { 2 - 3 } & PB & PMB \\
\hline Penetration $\left(25^{\circ} \mathrm{C}, 100 \mathrm{~g}, 5 \mathrm{~s}\right)(0.1 \mathrm{~mm})$ & 62.7 & 53.6 \\
Ductility $\left(5^{\circ} \mathrm{C}, 5 \mathrm{~cm} / \mathrm{min}\right)(\mathrm{cm})$ & 7.3 & 38.3 \\
Softening point $(\mathrm{TR} \mathrm{\&} \mathrm{B})\left({ }^{\circ} \mathrm{C}\right)$ & 47.2 & 68.7 \\
Density $\left(15^{\circ} \mathrm{C}\right)\left(\mathrm{g} / \mathrm{cm}^{3}\right)$ & 1.034 & 1.033 \\
Solubility (trichloroethylene) $(\%)$ & 99.9 & 99.7 \\
\hline
\end{tabular}

tures. Table 2 shows the properties of the aggregate. The filler has a $\mathrm{CaO}$ content of $48.2 \%, \mathrm{SiO}_{2}$ content of $1.46 \%$, and specific gravity of $2.734 \mathrm{~g} / \mathrm{cm}^{3}$.

\subsection{Preparation of PPA-modified asphalt}

PPA-modified binders were prepared using a rotation mixer at $4000 \mathrm{r} / \mathrm{min}$. First, asphalt about $100 \mathrm{~g}$ was heated into fluidity at around $160^{\circ} \mathrm{C}$ and $170^{\circ} \mathrm{C}$ for Pure Bitumen (PB) and Polymer Modified Bitumen (PMB) binders, respectively. Then, an appropriate amount of PPA (1.5 wt. \% of asphalt) was added to the hot liquid asphalt slowly and blended for 30 min to ensure that it could be dispersed well in binders. After that, all specimens for follow-up tests were prepared to evaluate the asphalt performances. To avoid interference in test conditions and ensure the test consistency, the control PB and PMB also experienced the same test process. Besides, in order to facilitate discussion, PPA-modified PB asphalt and PPA-modified PMB asphalt are denoted by PPA-PB and PPA-PMB, respectively.

\subsection{Preparation of PPA modified asphalt mixture}

A common dense-graded asphalt mixture (AC-13) was selected to prepare the PPA-modified asphalt mixture as it is widely used. Based on Chinese technical specifications (JTG F40, 2004) [18], the final composition of gradation was determined by the Marshall test and the results are given in Table 3 . The Marshall stability, flow values, and volumetric parameters of asphalt mixtures were measured to obtain the optimum asphalt contents according to the Marshall method (JTG F40, 2004, ASTM D1559). Table 4 shows the Marshall design results of these asphalt mixtures.

\subsection{Aging procedure for asphalt}

UV aging of PPA-modified asphalt was performed using TFOT first at $163^{\circ} \mathrm{C}$ for $5 \mathrm{~h}$ to simulate shortterm aging effect and, then, the TFOT residue was immediately put in an oven with a UV lamp to simulate the field UV aging in the service period. The temperature of UV aging was controlled at $60^{\circ} \mathrm{C}$ and the intensity of UV irradiation was $1000 \mathrm{w} / \mathrm{m}^{2}$ provided by a UV lamp. Three laboratory UV aging times (2 $\mathrm{d}, 4 \mathrm{~d}$, and $6 \mathrm{~d}$ ) were employed to characterize the 
Table 2. Properties of the used aggregate.

\begin{tabular}{lcc}
\hline \multicolumn{1}{c}{ Test properties } & Standard & Test results \\
\hline Coarse aggregate specific gravity $\left(\mathrm{g} / \mathrm{cm}^{3}\right)$ & ASTM C-127 & 2.823 \\
Coarse aggregate absorption (\%) & ASTM C-127 & 0.33 \\
Fine aggregate specific gravity $\left(\mathrm{g} / \mathrm{cm}^{3}\right)$ & ASTM C-128 & 2.821 \\
Fine aggregate absorption (\%) & ASTM C-128 & 0.41 \\
Abrasion loss (Los Angeles) (\%) & ASTM DC-131 & 8.1 \\
\hline
\end{tabular}

Table 3. Combined aggregate gradation.

\begin{tabular}{ccccccccccc}
\hline Sieve size (mm) & 16 & 13.2 & 9.5 & 4.75 & 2.36 & 1.18 & 0.6 & 0.3 & 0.15 & 0.075 \\
Total cumulative passing (\%) & 100 & 95 & 72 & 43 & 32 & 21 & 16 & 12 & 9 & 5 \\
\hline
\end{tabular}

Table 4. Marshall design results of asphalt mixtures.

\begin{tabular}{lcccc}
\hline \multirow{2}{*}{ Test properties } & \multicolumn{4}{c}{ Asphalt mixture } \\
\cline { 2 - 5 } & PB & PPA-PB & PMB & PPA-PMB \\
\hline Optimum Asphalt Content (OAC) (\%) & 4.6 & 5.0 & 4.9 & 5.2 \\
Air void (\%) & 4.2 & 4.1 & 4.3 & 4.2 \\
Voids in mineral aggregate (\%) & 13.91 & 14.22 & 14.16 & 14.35 \\
Voids filled with asphalt (\%) & 72.3 & 72.6 & 72.5 & 72.2 \\
\hline
\end{tabular}

performance changes of asphalt following UV aging time. Based on the ultraviolet irradiation of UV lamp, the amount of UV radiation per day is $1000 \mathrm{w} / \mathrm{m}^{2} \times$ $1 \mathrm{~d} \times 24 \mathrm{~h} \times 3600 \mathrm{~s}=8.64 \times 10^{7} \mathrm{~J} / \mathrm{m}^{2}$ in the experiment. According to $\mathrm{Hu}$ et al. [17], the annual $\mathrm{UV}$ radiation average is $0.91 \mathrm{MJ} \mathrm{m}{ }^{-2} / \mathrm{d}=9.1 \times 105$ $\mathrm{J} / \mathrm{m}^{2}$ in Lhasa, which is the strongest UV radiation in China. Therefore, the $1 \mathrm{~d}(24 \mathrm{~h}) \mathrm{UV}$ aging time in the laboratory amounts to $95 \mathrm{~d}$ in the external environment, while the $2 \mathrm{~d}, 4 \mathrm{~d}$, and $6 \mathrm{~d}$ UV aging times in this research could represent $190 \mathrm{~d}(0.52 \mathrm{y}), 380 \mathrm{~d}$ (1.04 y), and $570 \mathrm{~d}$ (1.56 y), respectively, in the field.

\subsection{Aging procedure for asphalt mixture}

According to the asphalt mix design results, the loose asphalt mixture with different binders was prepared in a mixer. The short-term aging of asphalt mixture was simulated by AASHTO R30, and the loose asphalt mixture was continuously heated for $4 \mathrm{~h}$ at $135^{\circ} \mathrm{C}$ in a forced draft oven. Then, the aged loose mixtures were placed in the oven with a UV lamp for $2 \mathrm{~d}, 4 \mathrm{~d}$, and $6 \mathrm{~d}$, respectively. The UV irradiation parameters of asphalt mixture were the same as those of asphalt. Finally, the UV aged asphalt mixtures were preserved for later experiments.

\section{Experimental plan}

\subsection{Microcosmic effect analysis}

FTIR experiment was mainly used to provide information on functional groups. In this study, the infrared spectra of asphalt samples were recorded by an EQUINOX-55 spectrometer (Brucher company, Germany). The scanning speed was 40 sheets per second, resolution $0.4 \mathrm{~cm}^{-1}$, and scanning range 4000 $400 \mathrm{~cm}^{-1}$.

Thermal properties of these asphalt samples were evaluated by TG analysis. In the process of TG testing, the temperature started from $50^{\circ} \mathrm{C}$ to $800^{\circ} \mathrm{C}$ with an air flow of $50 \mathrm{ml} / \mathrm{min}$ at a heating rate of $20^{\circ} \mathrm{C} / \mathrm{min}$.

\subsection{Asphalt performance test}

The properties of matrix asphalt and PPA-modified asphalts including penetration $\left(25^{\circ} \mathrm{C}\right)$, softening point, and ductility $\left(5^{\circ} \mathrm{C}\right)$ were measured to evaluate the UV aging behavior of PPA-modified asphalt in accordance with ASTM D5, ASTM D36, and ASTM D113-86, respectively. $\mathrm{G}^{*} / \sin \delta$ was used to characterize the rutting potential index of UV aging asphalt based on the DSR results through a Bohlin CVO 120 instrument. The standard procedure of DSR test followed AASHTO T 315.

UV aging resistance potential could be evaluated through the ratio, or a different value, of the performance parameter of UV aged asphalt to that of the unaged asphalt. The indices adopted in this research can be expressed as the Penetration Aging Index (PAI), Softening Point aging Index (SPI), Ductility Aging Index (DAI), and $\mathrm{G}^{*} / \sin \delta$ Aging Index (GAI). They can be defined as in the following equations:

$$
P A I=\frac{U V \text { aged penetration }}{\text { Unaged penetration }}
$$




$$
\begin{aligned}
& S P I=\frac{U V \text { aged softening point }}{\text { Unaged softening point }}, \\
& D A I=\frac{U V \text { aged ductility }}{\text { Unaged ductility }} \\
& G A I=\frac{U V \text { aged } G^{*} / \sin \delta}{U n \text { aged } G^{*} / \sin \delta} .
\end{aligned}
$$

Larger values of PAI, SPI, DAI, and GAI denote the worse aging of asphalt.

\subsection{Asphalt mixture performance test}

The performances of PPA-modified asphalt mixture (aged and unaged) including high-temperature stability, low-temperature cracking resistance, water stability, and anti-fatigue resistance were assessed and compared with those of matrix asphalt mixtures through the wheel tracking test, low-temperature bending beam test, freeze-thaw splitting test, and four-point bending beam fatigue test.

\section{Results of and discussion about asphalt performances}

\subsection{FTIR of UV aged PPA-modified asphalt}

To explore the changes in chemical structures of $\mathrm{PB}$ and PMB binders during the PPA modification process and UV aging process, FTIR spectra of these samples were tested. All absorbance spectra of these samples were superimposed in a graph to gain a better understanding of the relative difference in functional groups of different asphalt types. Figure 1(a) and (b) present the graphical FTIR absorbance against wavenumber.

From the results, it can be observed that the trends and shapes of absorbance spectra of PPAmodified samples are basically similar to those of the unmodified asphalt in the frequency region (4000-1330 $\left.\mathrm{cm}^{-1}\right)$. The peaks from $2754 \mathrm{~cm}^{-1}$ to $3100 \mathrm{~cm}^{-1}$ are the stretching vibrations of $\mathrm{C}-\mathrm{H}$; the small peak at $1597 \mathrm{~cm}^{-1}$ is caused by the stretching vibration of $\mathrm{C}=\mathrm{C}$; the $\mathrm{C}-\mathrm{H}$ bonds observed in the region of 1376-1462 $\mathrm{cm}^{-1}$ are classified as the $\mathrm{CH}_{2}$ and $\mathrm{CH}_{3}$ symmetric deformation vibrations. In the fingerprint region (from about 1330 to $400 \mathrm{~cm}^{-1}$ ), the absorption peaks of asphalt samples after PPA modification are different. Further to that, there is a new absorbance peak appearing in the $800-1330 \mathrm{~cm}^{-1}$, as caused by the bending vibration of phosphorus atoms (P-O-P).

However, based on a comparison of UV aged asphalt and unaged asphalt, it is clear that no new peak appeared, indicating that no new functional groups appeared in the molecule chain in the UV aging process. To further investigate the effect of UV aging and PPA modification on the asphalt, the band area ratio index is used to analyze the functional groups of the samples. The aging degree of asphalt can be evaluated and compared by a parameter called Carbonyl Index (CI), which is calculated by the following formula according to Lamontagne et al. [19]:

$$
C I=\frac{A_{C=O}}{A_{\text {ref }}},
$$

where $A_{C=O}$ is the integral area of carbonyl groups and $A_{\text {ref }}$ is the integral area ranging from $700 \mathrm{~cm}^{-1}$ to 2000 $\mathrm{cm}^{-1}$.

Based on Eq. (5), CI values of all asphalt samples are shown in Table 5. From the results, it can be observed that all CI values of asphalt increase after UV aging and the CI values of PPA-modified asphalt are lower than those of unmodified ones. To be specific, the CI values increase by $3.85 \%, 10.7 \%, 45.09 \%$, and $38.6 \%$ for PB, PPA-PB, PMB, and PPA-PMB after UV

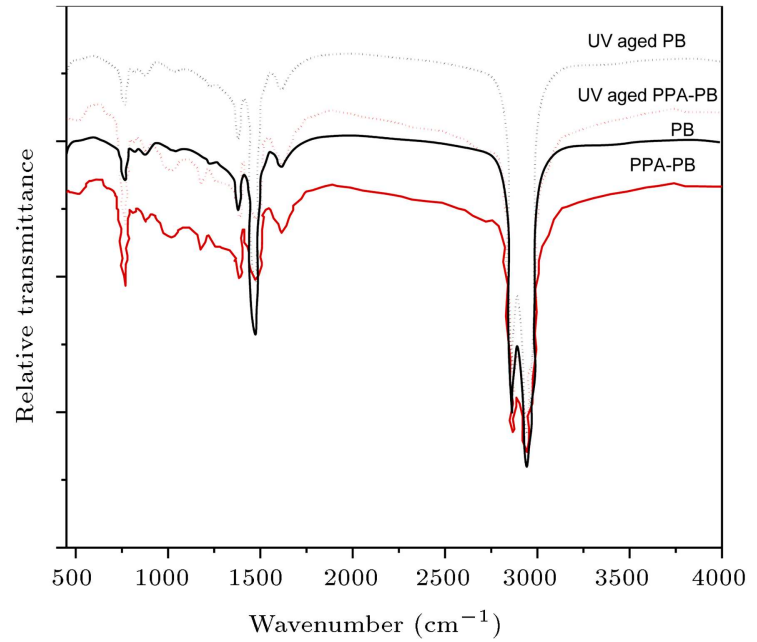

(a)

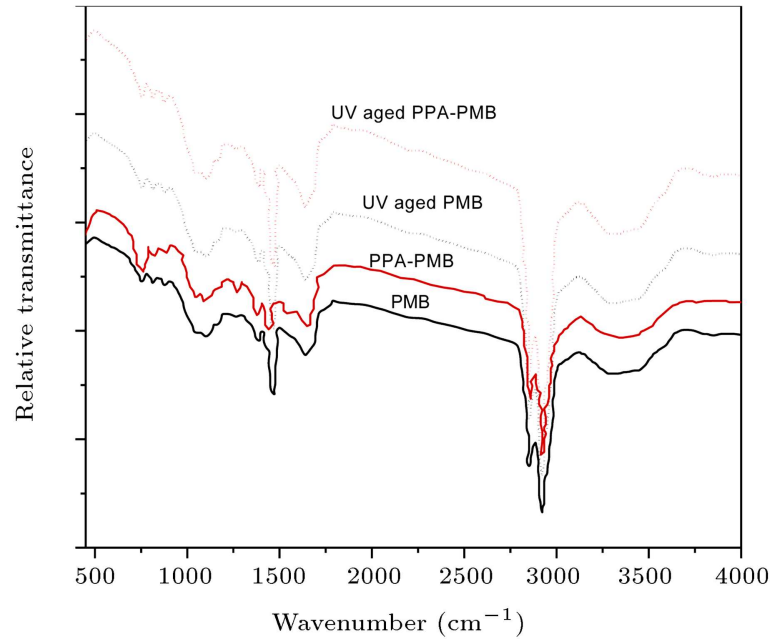

(b)

Figure 1. Fourier Transform Infrared Spectroscopy (FTIR) results of asphalt with Ultraviolet (UV) aged and unaged: (a) Pure Bitumen (PB) and (b) Polymer Modified Bitumen (PMB). 
Table 5. Carbonyl Index (CI) values of asphalt samples.

\begin{tabular}{ccccc}
\hline Types & PB & PPA-PB & PMB & PPA-PMB \\
\hline Unaged & 0.0312 & 0.030 & 0.0326 & 0.0321 \\
UV aged & 0.0324 & 0.0332 & 0.0473 & 0.0445 \\
\hline
\end{tabular}

aging, respectively. Conversely, following the addition of PPA, the CI values for PB and PMB in the unaged state are reduced by $3.85 \%$ and $1.5 \%$, while they are reduced by $2.47 \%$ and $5.91 \%$ in the UV aged state. Given that a large CI value suggests more carbonyl groups, it can be inferred that UV aging increases the number of carbonyl groups; however, the addition of PPA inhibits the increase of carbonyl in the oxidation process.

\subsection{TG analysis of UV aged PPA-modified asphalt}

With respect to the thermal characteristics of binders following PPA modification and UV aging, TG characteristics were measured and the results are shown in Figure 2. It can be seen that the loss of mass appears in the main decomposition temperature range (260$500^{\circ} \mathrm{C}$ ) for $\mathrm{PB}$ and PMB asphalt binders. Moreover, TG curves of unmodified/modified asphalt and UV aged/unaged binders are different. It is implied here that PPA and UV aging can change the thermal stability of asphalt. The starting point in the mass losstemperature curve appears at $267^{\circ} \mathrm{C}$ for $\mathrm{PB}$ and $293^{\circ} \mathrm{C}$ for $\mathrm{PMB}$, while following the addition of $\mathrm{PPA}$, it appears at $277^{\circ} \mathrm{C}$ for PPA-PB and $304^{\circ} \mathrm{C}$ for PPA-PMB. This shows that the addition of PPA delays the process of mass decomposition and makes asphalt more stable.

The Epitaxial Initiation Temperature (EIT), defined as a temperature at the intersection point between the tangent line of the descending branch and the base-line extension of TG curve, is usually used as an evaluating indicator of thermal stability, representing

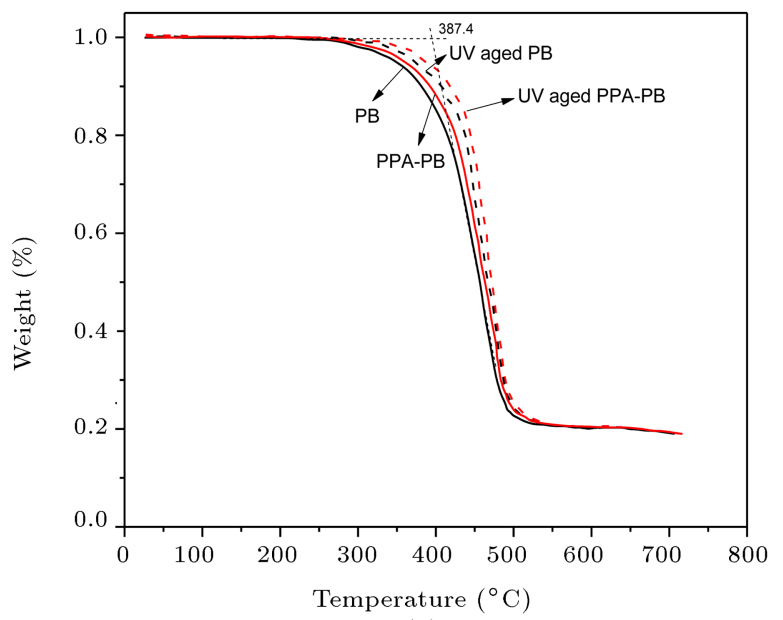

(a)
Table 6. Epitaxial Initiation Temperature (EIT) values of asphalt samples.

\begin{tabular}{ccccc}
\hline Types & PB & PPA-PB & PMB & PPA-PMB \\
\hline Unaged & $387.4^{\circ} \mathrm{C}$ & $395.3^{\circ} \mathrm{C}$, & $397.3^{\circ} \mathrm{C}$ & $404.9^{\circ} \mathrm{C}$ \\
UV aged & $404.7^{\circ} \mathrm{C}$ & $491.3^{\circ} \mathrm{C}$ & $404.7^{\circ} \mathrm{C}$ & $416.8^{\circ} \mathrm{C}$ \\
\hline
\end{tabular}

its excellent repeatability. The intersections of $\mathrm{PB}$ and PMB are presented in Figure 2 in this research. Through analysis, EIT values of all asphalt samples are listed in Table 6. It can be found that the EIT values of PB and PMB increased due to PPA and UV aging. To be specific, when PPA is added to asphalt, the EIT values of $\mathrm{PB}$ and $\mathrm{PMB}$ in the unaged state increase by $2.1 \%$ and $1.9 \%$, while after UV aging, the EIT values of $\mathrm{PB}$ and $\mathrm{PMB}$ increase by $4.5 \%$ and $1.8 \%$. This may be attributed to the PPA, and UV aging could prompt the polycondensation of light components in asphalt. Therefore, the addition of PPA increases asphaltene content and improves the thermal stability of the binder.

\subsection{Penetration test}

Penetration could reflect the soft degree and consistency of asphalt. Figure 3 illustrates the penetration results at $25^{\circ} \mathrm{C}$ for different binders at different $\mathrm{UV}$ aged times. Figure 3 clearly shows that all penetration values of asphalt binders decrease upon increase in UV aging time, which implies that asphalt will harden with the UV aging. Furthermore, the penetration decrement of PPA-modified asphalt was smaller than that of the unmodified asphalt following UV aging. Take $6 \mathrm{~d}$ UV aging as an example. The penetration was reduced by about $40.3 \%, 32.8 \%, 38.4 \%$, and $33.2 \%$ for PB, PPA$\mathrm{PB}, \mathrm{PMB}$, and $\mathrm{PPA}-\mathrm{PMB}$, respectively. In addition, as shown in Figure 3(b), PAI is reduced in the case of PPA, while it experiences an increment after UV aging. Given that higher PAI represents a higher

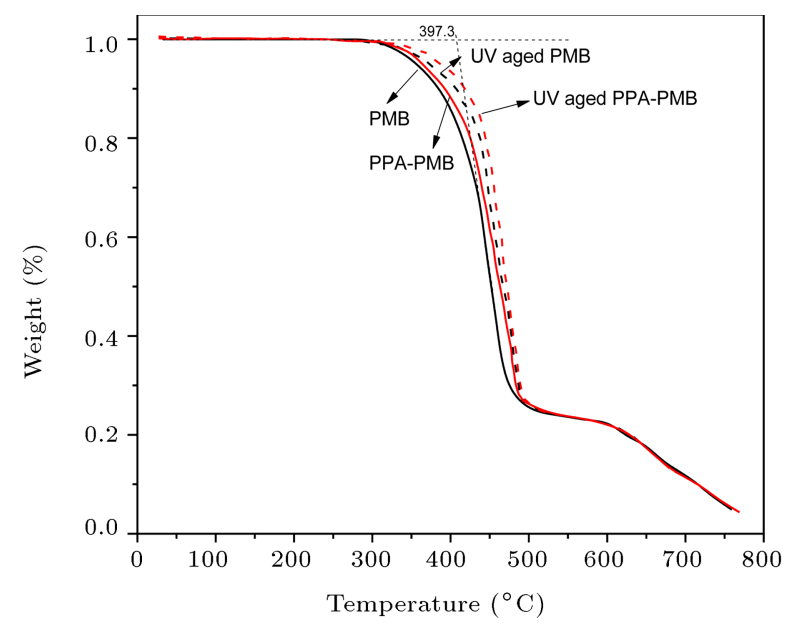

(b)

Figure 2. Thermo-Gravimetric (TG) results: (a) Pure Bitumen (PB) and (b) Polymer Modified Bitumen (PMB). 


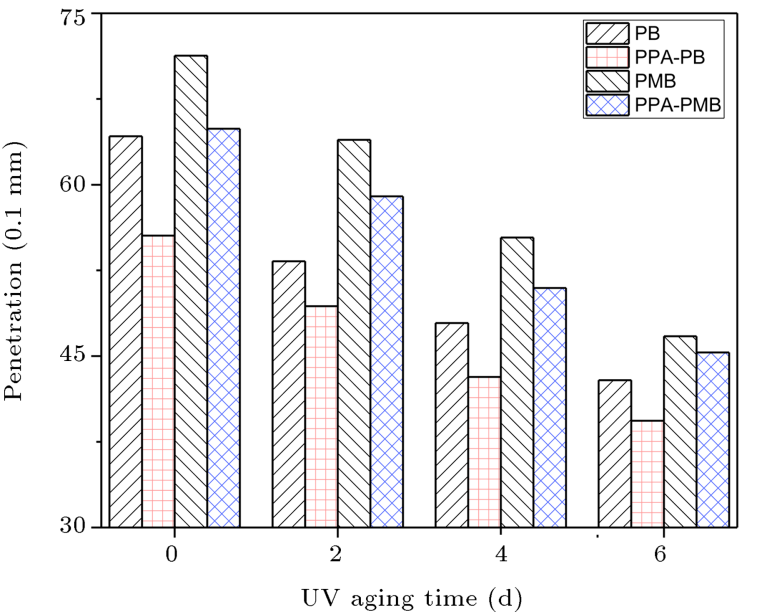

(a)

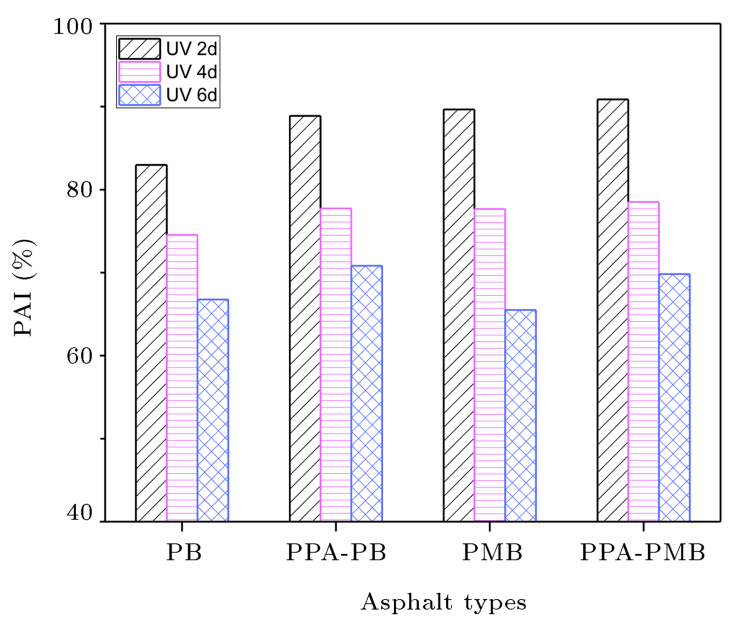

(b)

Figure 3. Penetration test: (a) Penetration value and (b) penetration aging index.

degree of aging, it can be concluded that PPA enjoys low-temperature performance in UV aged asphalt. In other words, the addition of PPA will relieve UV aging hardening effects.

\subsection{Softening point test}

The softening point results of asphalt samples at different UV aged times are shown in Figure 4. Compared with the corresponding matrix asphalt, PPA-modified asphalts have higher softening point values. In particular, the softening point of $\mathrm{PB}$ asphalt experiences increase after the addition of PPA. Furthermore, UV aged asphalts have higher softening point values than unaged binders due to UV aging hardening effect. Besides, the increment of softening point is lower for PPA-modified asphalt than that of the unmodified asphalt before and after UV aging. For example, after $6 \mathrm{~d}$ UV aging, the softening point values increase by about $45.8 \%, 13.1 \%, 46.8 \%$, and $35.7 \%$ for PB, PPA$\mathrm{PB}, \mathrm{PMB}$, and PPA-PMB, respectively. According to

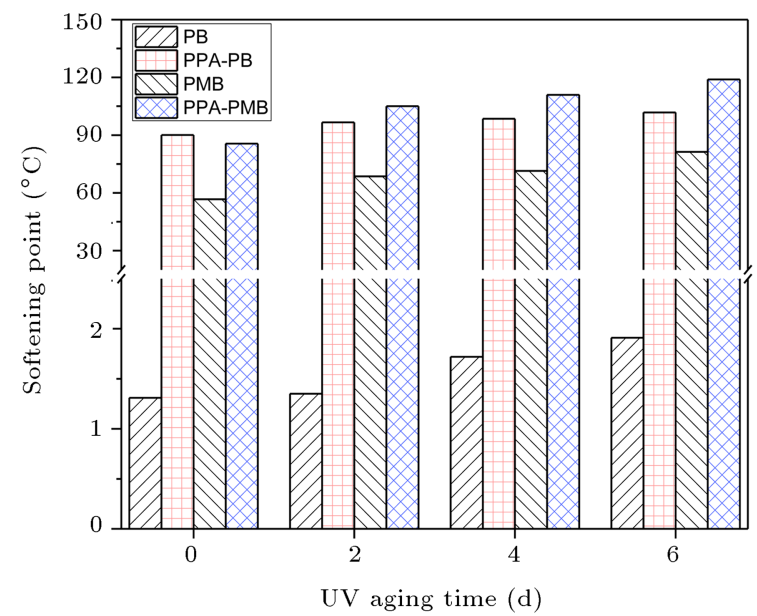

(a)
Figure 4 (b), although the SPI increases with the UV aging, the addition of PPV decreases the SPI value. This means that the hardening effect of UV aging on the softening point can be counteracted by the PPA.

\subsection{Ductility test}

Ductility characterizes the flexibility and deformation of binders. Figure 5 shows the ductility values and DAI of asphalt samples at different UV aging times. It can be seen that the ductility of binders increases upon PPA addition, meaning an improvement to PPA with low-temperature flexibility and crack resistance. Additionally, compared with the ductility of the corresponding unaged asphalts, UV aged asphalt-modified binders display lower ductility, indicating the physical hardening process of asphalt in UV aging for all binders. For example, PPA-PMB at 2-day UV aging owns ductility of $33.4 \mathrm{~cm}$ which is lower than that of the unaged binder with $45.5 \mathrm{~cm}$. Furthermore, from Figure 5(b), it can be seen that although DAI values

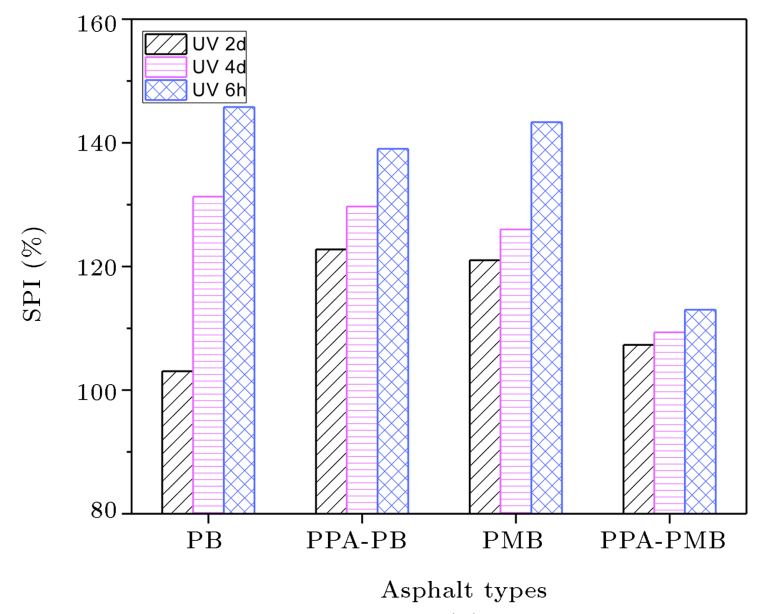

(b)

Figure 4. Softening point test: (a) Softening point value and (b) softening point aging index. 


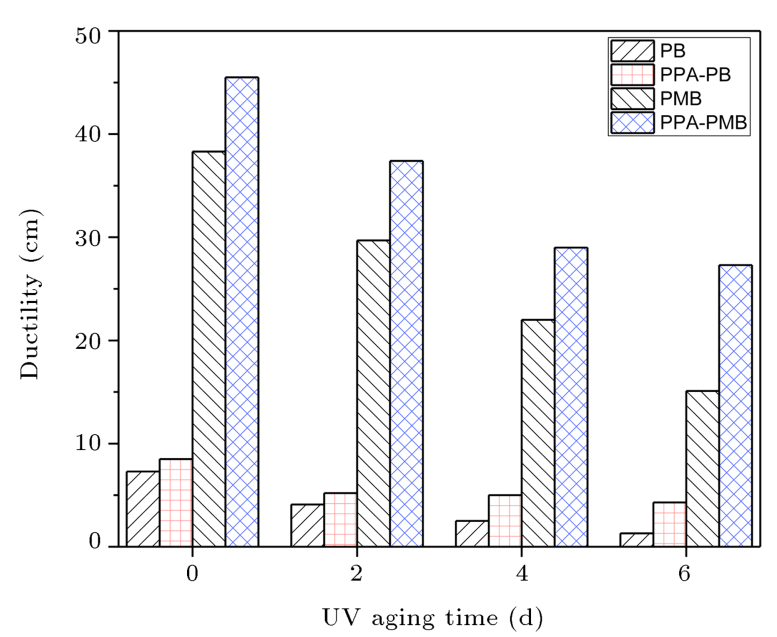

(a)

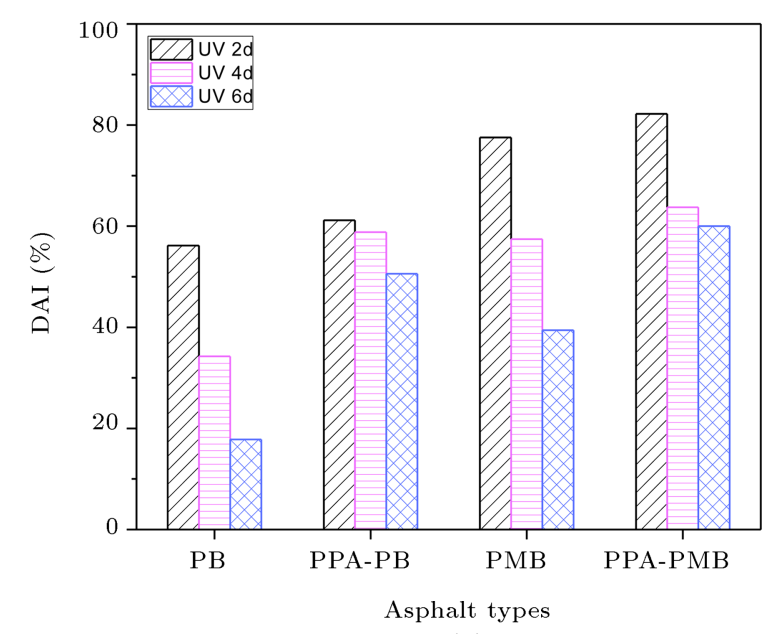

(b)

Figure 5. Ductility test: (a) Ductility value and (b) ductility aging index.

of all binders are reduced after increase in UV aging times, the addition of PPA obviously increases DAI of the modified PB and PMB binders. Considering that a larger DAI is characterized by a less serious aging degree, it can be seen that PPA contributes to the lowtemperature performance of UV aged asphalt.

\section{6. $G^{*} / \sin \delta$ test}

The unrecoverable deformation of asphalt is often characterized by the rutting resistance factor $\left(\mathrm{G}^{*} / \sin \delta\right)$. In general, higher $\mathrm{G}^{*} / \sin \delta$ and smaller flow deformation at high temperatures suggest the higher rutting resistance of asphalt. The results of $\mathrm{G}^{*} / \sin \delta$ for all asphalt samples at different UV aging times are shown in Figure 6. In consequence, $\mathrm{G}^{*} / \sin \delta$ of asphalt is influenced by PPA and UV aging and $\mathrm{G}^{*} / \sin \delta$ increases upon the addition of PPA and UV aging time. Take the $\mathrm{PB}$ binder as an example; when PPA is added to asphalt, $\mathrm{G}^{*} / \sin \delta$ of PPA-PB increases by $240.7 \%$. However, when UV aging time is $2 \mathrm{~d}, 4 \mathrm{~d}$, and

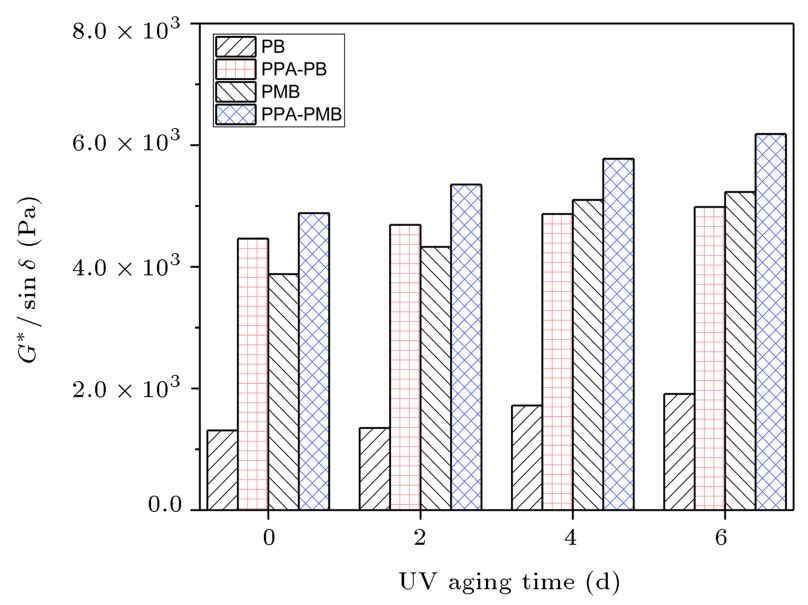

(a)
$6 \mathrm{~d}, \mathrm{G}^{*} / \sin \delta$ of PB increases by $3.05 \%, 31.29 \%$, and $45.8 \%$, respectively. These results indicate that PPAmodified binders exhibit better rutting resistance than unmodified ones. In particular, $\mathrm{G}^{*} / \sin \delta$ of all binders shows a clear increase in an ascending pattern upon the increase of UV aging time. It can be proven that the PPA and UV aging will harden asphalt. Furthermore, According to Figure $6(\mathrm{~b})$, although $\mathrm{G}^{*} / \sin \delta$ increment of all binders grows significantly after aging, PPAmodified asphalt still experiences smaller increment than the unmodified asphalt. Since smaller increment indicates a lower degree of aging, this result shows that PPA contributes to the high-temperature performance of UV aged asphalt.

\section{Asphalt mixture performances}

\subsection{Wheel tracking test}

Wheel tracking test was carried out to report the hightemperature performance of PPA-modified asphalt

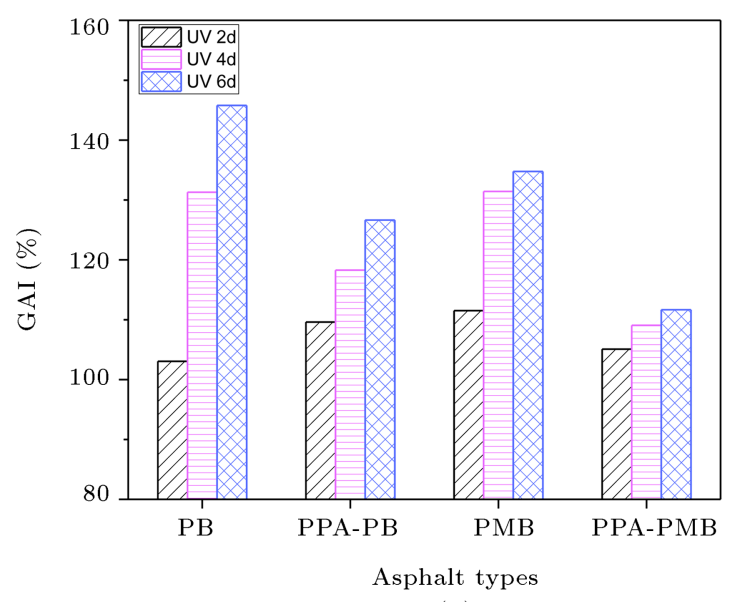

(b)

Figure 6. Rutting resistance factor result: (a) $\mathrm{G}^{*} / \sin \delta$ and (b) $\mathrm{G}^{*} / \sin \delta$ aging index. 
mixture at different UV aging times. This experiment condition was standardized as loading for $0.7 \mathrm{MPa}$, temperature for $60^{\circ} \mathrm{C}$, and wheel running speed for 42 cycles/min, with a rubber wheel of $50 \mathrm{~mm}$ width by the Chinese experiment specification (JTG E20-2011) [20]. To ensure the high accuracy of the experiment results, three replicates were used for each sample. Then, rutting depth (unrecoverable displacement) was recorded to calculate Dynamic Stability (DS) through Eq. (6) according to JTG E20-2011.

$$
D S=\frac{15 N}{d_{60}-d_{45}}=\frac{15 \times 42}{d_{60}-d_{45}},
$$

where $N$ means the wheel loading cycles per minute and it is 42 cycles/min in this research; $d_{45}$ and $d_{60}$ denote the rutting depths of asphalt mixture at 45 and 60 minutes, respectively.

The dynamic stability of PB and PMB asphalt mixtures at different UV aging times is shown in Figure 7. As shown in Figure 7, the dynamic stability of asphalt mixture samples improved with the addition of PPA. For example, when 1.5 wt. \% PPA was added to $\mathrm{PB}$ and $\mathrm{PMB}$ in the unaged state, the $\mathrm{DS}$ values of both asphalt cases increased by $133.1 \%$ and $42.96 \%$, respectively. Furthermore, DS values of asphalt mixtures after UV aging experienced an increment. For the PB asphalt, the DS values increased by $4.59 \%, 10.51 \%$, and $15.91 \%$ for $2 \mathrm{~d}, 4 \mathrm{~d}$, and $6 \mathrm{~d}$, respectively. In addition, for the PMB asphalt, the DS values increased by $12.91 \%, 19.25 \%$, and $20.44 \%$ for $2 \mathrm{~d}, 4 \mathrm{~d}$, and $6 \mathrm{~d}$, respectively. Therefore, it can be pointed out that both PPA modification and UV aging could improve hightemperature performances of asphalt, but the degree of their effects on asphalt sources varies. Moreover, PPAmodified asphalt underwent minor changes as the UV aging time increased, as compared to the unmodified asphalt. For PB and PMB asphalt mixtures without PPA, the DS values increased by $116 \%$ and $121 \%$ when

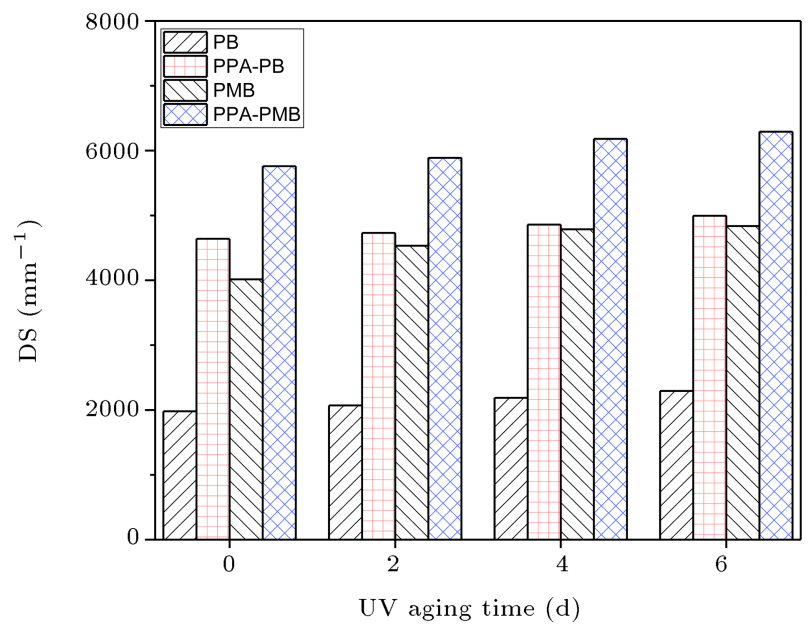

Figure 7. Wheel tracking test results.
UV aging time was 6d; however, for $\mathrm{PB}$ and $\mathrm{PMB}$ asphalt mixtures with PPA, the DS values increased by $108 \%$ and $109 \%$. These results indicate that PPA can attenuate the effect of UV aging on the hightemperature performances of asphalt.

\subsection{Low-temperature bending beam test}

Low-temperature properties of asphalt mixtures in different aging states were evaluated using bending test at $-10^{\circ} \mathrm{C}$ with $250 \mathrm{~mm} \times 50 \mathrm{~mm} \times 50 \mathrm{~mm}$ beam specimens under $50 \mathrm{~mm} / \mathrm{min}$. The vertical deflection at the center of asphalt beam and its load application were recorded until the beam was broken, and tensile failure strain was calculated through Eq. (7).

$$
\varepsilon_{b}=\frac{6 \times h \times d}{L^{2}}
$$

where $\varepsilon_{b}$ and $d$ denote the tensile failure strain and vertical displacement when the beam is fractured, and $h$ and $L$ denote the dimensions of the asphalt beam (height, length).

The average values of tensile failure strain and the low-temperature aging index values of the asphalt mixture samples are shown in Figure 8. It can be seen that the failure strain of all asphalt mixture samples is reduced upon the lengthening of UV aging time, meaning that a lower amount of energy is needed to destroy the specimen at low temperatures. In other words, UV aging weakens the performance of asphalt mixture at low temperatures. Furthermore, PPA-PB asphalt mixtures have lower failure strain values than control $\mathrm{PB}$ asphalt mixtures in aged and unaged conditions. For example, at $2 \mathrm{~h}$ aging time, the failure strains of PPA-PB and PB are $2455 \mu \varepsilon$ and $2683 \mu \varepsilon$, while the failure strains of PPA-PMB and PMB are $4116 \mu \varepsilon$ and $4558 \mu \varepsilon$, respectively. These results reflect the lowtemperature properties of asphalt mixture jeopardized by UV aging, and the addition of PPA retards its aging effect.

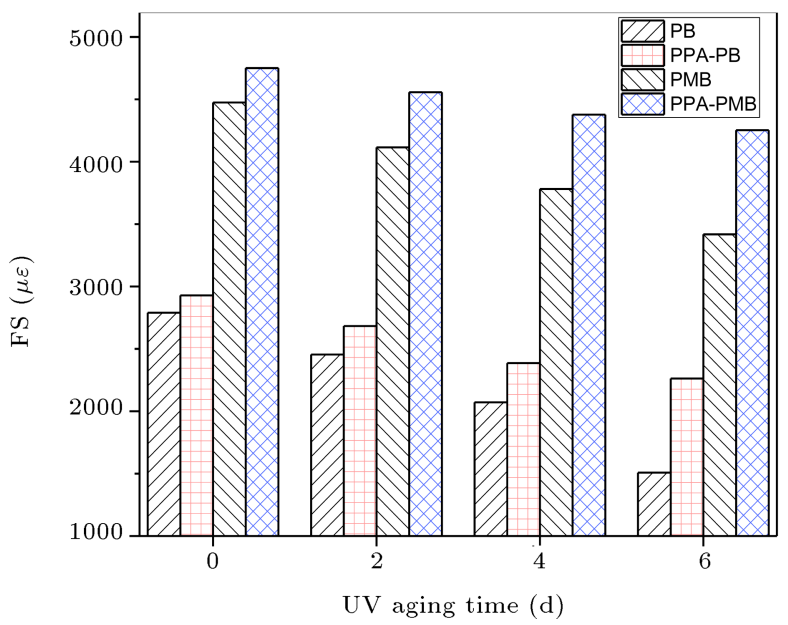

Figure 8. Low-temperature bending beam test results. 


\subsection{Freeze-thaw splitting test}

Freeze-thaw splitting test was employed to study the effect of PPA on the moisture stability of UV aged asphalt mixtures. Eight specimens of asphalt mixtures with a diameter of $100 \mathrm{~mm}$ and a height of $150 \mathrm{~mm}$ were divided into two groups. Four specimens were used as a control group, and the other specimens were used as the test group. The specimens of the test group immersed in water were placed in a vacuum box for $15 \mathrm{~min}$ first and, then, were frozen for $16 \mathrm{~h}$ in an environment chamber at $-18^{\circ} \mathrm{C}$; after that, these specimens were saturated in water bath for $24 \mathrm{~h}$ at $60^{\circ} \mathrm{C}$. Tensile Strength Ratio (TSR) calculated through Eq. (8), which is defined as the tensile strength of a test specimen compared to the control specimen, was used to evaluate the water stability of asphalt mixture.

$$
T S R=\frac{R_{2}}{R_{1}} \times 100
$$

where $R_{2}$ and $R_{1}$ are the tensile strength values of the specimens of test and control groups, respectively.

The TSR results of PPA asphalt mixture samples in different UV aging periods are shown in Figure 9. It was found that the PPA-modified asphalt mixtures had higher TSR than control mixtures, which showed that the addition of PPA could improve the moisture susceptibility of asphalt mixture. Furthermore, upon the lengthening of UV aging time, the TSR of asphalt mixture with or without PPA modifications was reduced obviously. This finding indicated that UV aging could jeopardize the water stability of the asphalt mixture; therefore, aging could make asphalt hardened and reduce its cohesiveness. Based on these results, it becomes clear that PPA could facilitate the water stability of asphalt mixtures. This means that PPA could intensify the moisture susceptibility of UV aged asphalt mixtures.

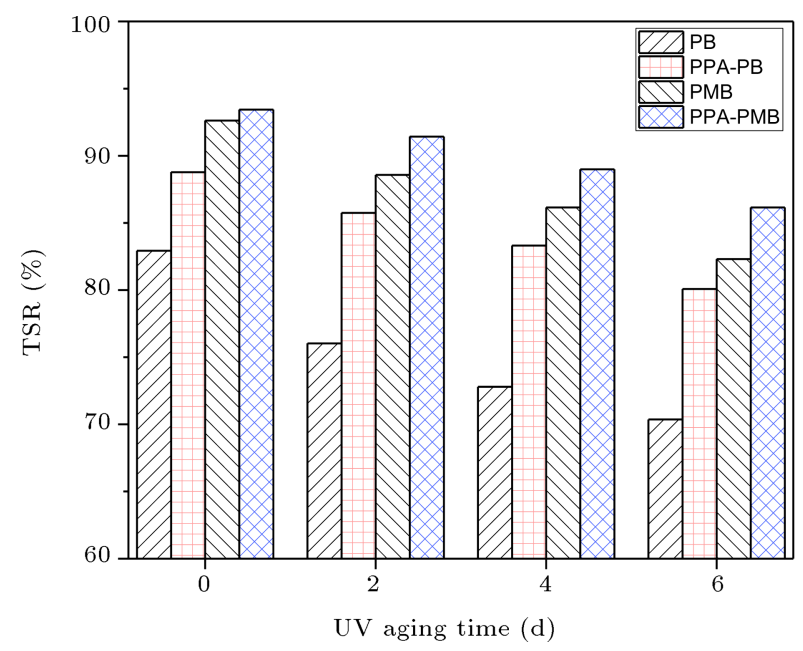

Figure 9. Freeze-thaw splitting results.

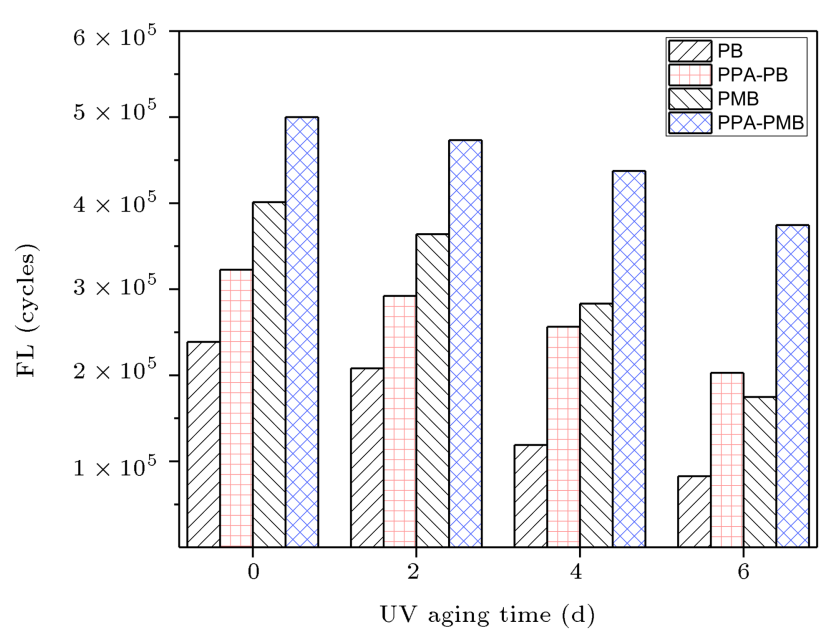

Figure 10. Four-point bending fatigue tests results.

\subsection{Fatigue test}

Four-point bending fatigue tests were conducted to estimate the fatigue life of the asphalt mixture specimens based on strain control test mode. Specimens with $400 \mathrm{~mm} \times 50 \mathrm{~mm} \times 65 \mathrm{~mm}$ were tested under partial sinusoidal stress at a loading frequency of $10 \mathrm{~Hz}$ and a strain ratio of 0.20 . The number of loading cycles corresponding to the stiffness was reduced in half, denoting the fatigue life of asphalt mixture. Figure 10 shows the fatigue life of PPA-modified asphalt mixture in different UV aging time periods. Similar to the trend of low-temperature performance and moisture susceptibility, the fatigue lives of all specimens increase upon the addition of PPA and decrease with the elongation of the UV aging time. These results prove that the addition of PPA could increase the fatigue life and attenuate the UV aging effect on the fatigue property.

\section{Conclusions}

This study investigated the physical, rheological, and chemical characterization of Ultraviolet (UV) aging behaviors of Polyphosphoric Acid (PPA)-modified asphalt and its mixtures. By comparing the differences in the performances of asphalt and asphalt mixtures with or without PPA in different UV aging states, the following conclusions can be summarized:

- In the process of UV aging, performance parameters such as softening point, $\mathrm{G}^{*} / \sin \delta$, and dynamic stability increased, while penetration, ductility, tensile strength ratio, and fatigue life decreased following the elongation of UV aging times;

- FTIR analysis results indicated that the mechanisms of PPA modified-asphalt were physical and chemical reactions when oxidation occurred in matrix asphalt and PPA-modified asphalt in the UV aging process, 
while the mechanisms of PPA modified asphalt were physical and chemical reactions;

- Thermo-Gravimetric (TG) analysis results showed that both UV aging and PPA could promote the polycondensation of light components in asphalt. Therefore, the thermal properties of binders were improved by the UV aging and PPA modification;

- According to the tests done on asphalt and asphalt mixtures, the introduction of PPA could enhance the thermal stability of asphalt binders and improve the pavement performances of asphalt mixture;

- The introduction of PPA could prevent the structural breaks or cracks in asphalt during oxidation, which restricts the effect of UV aging on the asphalt and asphalt mixture and improves the aging performance of asphalt and asphalt mixtures.

\section{Acknowledgments}

The research presented herein was sponsored by the National Natural Science Foundation of China (NSFC) (No. 51908194), the Key Research and Development Program of Jiangxi (20192BBG70080), the Fundamental Research Funds for the Central Universities (B200202071), the Guangxi Natural Science Foundation Program (2018GXNSFAA281339), the Foundation of Jiangxi Transportation and Technology Project (2018Q0027), the China Postdoctoral Science Foundation Project (2019M650101).

\section{References}

1. Yu, J.Y., Feng, P.C., Zhang, H.L., et al. "Effect of organo-montmorillonite on aging properties of asphalt", Construction \& Building Materials, 23(7), pp. 2636-2640 (2009).

2. Li, Y., Moraes, R., Lyngdal, E., et al. "Effect of polymer and oil modification on the aging susceptibility of asphalt binders", Transportation Research Record: Journal of the Transportation Research Board, 2574, pp. 28-37 (2016).

3. Liu, G., Nielsen, E., Komacka, J., et al. "Rheological and chemical evaluation on the ageing properties of SBS polymer modified bitumen: From the laboratory to the field", Construction \& Building Materials, 51, pp. 244-248 (2014).

4. Menapace, I. and Masad, E. "Evolution of the microstructure of warm mix asphalt binders with aging in an accelerated weathering tester", Journal of Materials in Civil Engineering, 29(10), 04017162 (2017).

5. Catalgol, B., Ziaja, I., Breusing, N., et al. "The proteasome is an integral part of solar ultraviolet a radiation-induced gene expression", Journal of Biological Chemistry, 284(44), pp. 30076-30086 (2009).
6. Durrieu, F., Farcas, F., and Mouillet, V. "The influence of UV aging of a Styrene/Butadiene/Styrene modified bitumen: Comparison between laboratory and on site aging", Fuel, 86(s10-11), pp. 1446-1451 (2007).

7. Zhang, F., Yu, J.Y., and Han, J. "Effects of thermal oxidative ageing on dynamic viscosity, TG/DTG, DTA and FTIR of SBS- and SBS/sulfur-modified asphalts", Construction \& Building Materials, 25(1), pp. 129-37 (2011).

8. Naskar, M., Reddy, K.S., Chaki, T.K., Divya, M.K., and Deshpande, A.P. "Effect of ageing on different modified bituminous binders: comparison between RTFOT and radiation ageing", Mater Struct, 46, pp. 1227-1241(2013).

9. Zhang, F. and Yu, J. "The research for highperformance SBR compound modified asphalt", Construction \& Building Materials, 24(3) pp. 410-418 (2010).

10. Singh, D., Ashish, P.K., Kataware, A., et al. "Evaluating performance of PPA-and-Elvaloy-modified binder containing WMA additives and lime using MSCR and LAS tests", Journal of Materials in Civil Engineering, 29(8), 04017064 (2017).

11. Domingos, M.D.I. and Faxina, A.L. "Rheological behaviour of bitumens modified with PE and PPA at different MSCR creep-recovery times", International Journal of Pavement Engineering, 16(9), pp. 1-13 (2015).

12. Jafari, M., Babazadeh, A., and Rahi, M. "Evaluating rutting and fatigue characteristics of binder containing SBS and PPA and their relationship with the mixture stiffness parameter", Journal of Materials in Civil Engineering, ASCE, 29(9), 04017143 (2017).

13. Alam, S. and Hossain, Z. "Changes in fractional compositions of PPA and SBS modified asphalt binders", Construction \& Building Materials, 152, pp. 386-393 (2017).

14. Baldino, N., Gabriele, D., Rossi, C.O., et al. "Low temperature rheology of polyphosphoric acid (PPA) added bitumen", Construction \& Building Materials, 36, pp. 592-596 (2012).

15. Huang, S., Turner, T.F., Miknis, M.F.P., et al. "Longterm aging characteristics of polyphosphoric acidmodified asphalts", Transportation Research Record: Journal of the Transportation Research Board, 2051, pp. 1-7 (2008).

16. Huang, S., Miknis, F.P., Schuster, W.C., et al. "Rheological and chemical properties of hydrated lime and polyphosphoric acid-modified asphalts with long-term aging", Journal of Materials in Civil Engineering, ASCE, 23(5), pp. 628-637 (2011).

17. Hu, B., Wang, Y.S., and Liu, G.R. "The characteristics of ultraviolet radiation in arid and semi-arid regions of 
China", Journal of Atmospheric Chemistry, 67(2-3), pp. 141-155 (2010).

18. Ministry of Transport of the People's Republic of China, Technical Specification for Construction of Highway Asphalt Pavement, Beijing (2004).

19. Lamontagne, J., Dumas, P., Mouillet, V., et al. "Comparison by Fourier transform infrared (FTIR) spectroscopy of different ageing techniques: application to road bitumens", Fuel, 80(4), pp. 483-488 (2001).

20. Ministry of Transport of the People's Republic of China, Standard Test Methods of Bitumen and Bituminous Mixtures for Highway Engineering, Beijing (2011).

\section{Biographies}

Shengjie Liu received his $\mathrm{PhD}$ in Road Engineering from the University of Chang'an in 2015. He is an Assistant Professor in Civil and Transportation at Hohai University since 2015. Dr. Liu has 10 years of practical and research experience in pavements engineering and materials. In his career, he has completed research projects on a wide range of subjects including pavement mechanistic design, warm mix asphalt, rubber asphalt, micromechanical models for pavement materials, and bioasphalt.

Yinshan $\mathbf{X u}$ received his $\mathrm{PhD}$ in Road Engineering from the University of Chang'an in 2017. He is a senior engineer at Zhejiang Scientific Research Institute of Transport. In his career, he has completed research projects on a wide range of subjects including pavement mechanistic design, pavement detection, and pavement maintenance.

Shengbo Zhou received his $\mathrm{PhD}$ in Road Engineering from the University of Chang'an in 2014. He is a senior engineer in Guangxi Transportation Research Institute. In his career, he has completed research projects on a wide range of subjects including pavement mechanistic design, warm mix asphalt, and pavement management. 